\title{
REGULATION MISUNDERSTANDING: CONVERGENCE COMPLEXITY PROVIDING FAILURES IN TELECOMMUNICATION SERVICES COSTS
}

\author{
Emílio José Montero Arruda Filho \\ School of Business, University of Amazonia (UNAMA), Brazil \\ School of Business, University FUMEC, Brazil.
}

\begin{abstract}
This manuscript discusses a theoretical competitive scenario for telecommunications services, in particular voice over Internet protocol (VoIP), and finds that the economic benefits of the current technological convergence are based on three main factors: technological advances and updates; regulation failures related to technological complexity; and consumer inability to exploit the benefits of convergence. This study begins by giving the background to voice communication in the telecommunications sector and the misunderstanding of the competitive boundaries between technologies, service providers, and usage applications generated in an unregulated sector. Second, the kinds of regulation that organizes the development and pricing of integrated or bundled services are briefly discussed and presented. Third, theoretical analysis of the competitive environment is interpreted in terms of the three factors: technological advances, regulation failure, and consumer knowledge of convergence. Results derived from these factors are presented in the context of VoIP services. Finally, the work concludes by outlining the implications for regulatory reform and the impact on competitive behavior, and describes possibilities for the future management of the technology sector.
\end{abstract}

Keywords - Competition, Emerging markets, Regulation, Strategy, Technology convergence, Consumer behavior.

\section{INTRODUCTION}

Most US communication companies are now integrated (Shelanski, 2007; Cicekli, 2011), and are capable of offering television, Internet, and voice communication (telephone) via a single unique connection to the customer's premises (Nunes et al., 2000). For voice communication specifically, different suppliers are able to offer landline, mobile and voice over Internet protocol (VoIP) as a result of technological convergence (Xavier and Ypsilanti, 2007; Gill, 2008), and it is possible to communicate with anyone in any part of the world using these different types of technologies (Hameria \& Paatela, 2005). Thanks to multiple technologies it is possible to identify users automatically, even when their mobile is turned 
off. When this happens, an electronic message can be left by redirecting the call to a landline or e-mail inbox, leaving a voice message as an e-mail to the user being searched for. It is also possible to redirect an internal number to the user company (Fenton et al., 2000) in cases in which the system is integrated with the enterprise system Digital Enhanced Cordless Telecommunications (DECT).

In this dynamic and aggressive telecommunications market, competitors face an uneven playing field. Telecom providers with large investments in physical infrastructure are able to take greater advantage of regulatory structures and maximize their revenues, creating unfair competition between voice communication (landline or mobile) and Internet companies. VoIP, which can be viewed as an added-value service rather than a voice communication service (Cohen et al., 2005), allows telecommunications providers to include it in the costs of infrastructure development (Jussawalla, 1999; Pathak, 2005) and to use the technology to reduce costs without transferring any cost savings to the customer. Internet companies, on the other hand, do not fall within the purview of telecom regulations and are, thus, unable to take advantage of the ways in which voice communication costs and prices are determined.

To guarantee a fair competitive environment in this sector, a strong regulatory policy should be developed for VoIP services because voice and data traffic in the IP networks look similar in their transmissions (Maeda et al., 2006). In the future, regulation will have to address how to harness technological advancements to deliver public benefits, as well as to avoid market failure. The main focus of this paper is to present the argument that it is not sufficient to attend to the minimum specifications related to quality and competitiveness in the telecommunications sector. This is particularly relevant for the regulatory authorities that deal with telecommunications where the technology is highly complex and dynamic, unlike, for instance, the transport sector, in which technological changes are much slower.

As example, if a Boston-based customer uses his mobile phone to place a call while traveling in California, the call can be connected via several possible paths. If the mobile service provider uses VoIP to make the coast-to-coast connection and stays within its own integrated networks, this service would not come under the purview of any regulator and the provider would be able to take advantage of new integrations to reduce costs, without transferring any advantages to the consumer (De Boer \& Evans, 1996; Carpenter \& Lapuerta, 1999). As long as VoIP is used as a tool to make connections between PCs, it would be seen as added value rather than voice communication, and would not fall within the regulatory framework. On the other hand, if the phone connection requires several different networks landline and mobile, as well as different service providers - then various regulators would have jurisdiction over issues such as cost, quality, usage, taxes, and fees, among others. In this process, however, the competitive field becomes unfair. This is because, technologically, the digital data compression model applied in phase shift keying (PSK) serves to transport voice in long-distance communications. It is still the best quality in use today and is able to transmit 120 voice channels over a $2 \mathrm{MB}$ data or voice communication channel (Fennel Jr. \& Gobioff, 1983). With the same 2 MB communication channel, a data communication system which converts voice to data, trafficking as VoIP (Korzeniowski, 2001), can transmit up to 240 voice channels simultaneously. By inserting new transmission technology, the same cable would be 
able to double the number of voice communications. Since VoIP is not regulated, there is no way for the regulation departments to know which type of protocol is being used by the provider companies (Liu et al., 2005); this leaves the possibility that for long-distance communications any provider that has fiber optics, cable, satellite, or some band of satellite communication can double the number of calls or reduce their bands, positively affecting their costs and revenues. Customers, even large customers, as well as regulators overseeing public utilities are less likely to link the costs and fees to the underlying technologies (Trebing, 2004; Sappington, 2005).

The convergence among services and competitors (Han et al., 2009) of each service makes it possible for specific telecom providers to reduce costs without passing on the savings to their customers, and prevents the regulators from recognizing the cost savings. To make this argument, we use several different perspectives to shed some light on the regulatory problems created by convergence in telecommunications services. The first - systems integration (SI) - refers to the integration of different technologies that is capable of developing services of two or more products (Hobday et al., 2005) - for instance, a 3-in-1 machine offering the capabilities of previously separate copy, fax, and scanner machines. The second - technology convergence (TC) - refers to convergence among different services or to different routes (Pathak, 2005) in which communication of the same quality, for instance over a landline network, can involve two or more providers - for example, placing a call to a landline number in another country via a mobile phone and calling an 800 number that uses VoIP to make the connection between two countries. The price for each type of call - local, interurban, international, and mobile, among others - will be differentiated by the schedule of each different provider. The presence of a high quantity of SI and TC in the market (Lee, 2007) leads to a lack of clear understanding of technology usage by telecoms providers and a lack of regulation by competent authorities that currently evaluate each service as a separate product.

This paper is divided into the following parts. First, the paper provides an overview of the developments in the telecommunications sector and the blurring of competitive boundaries between technologies, service providers, and usage applications. Second, the regulations that govern deployment and pricing of service bundles are briefly reviewed. Third, a theoretical analysis of the competitive environment is presented in terms of three factors: technological advancements, regulation failure, and consumer knowledge of convergence. The consequences of these factors are presented in the context of VoIP services. Finally, the implications for regulatory reform and the impact on competitive behavior are presented.

\section{SYSTEMS INTEGRATION (SI)}

\subsection{LONG-DISTANCE LANDLINE}

Landline service providers have a responsibility to provide voice and data communication in their local (metropolitan) region as well as medium- and long-distance communications; to be considered long-distance, these may be within the state (medium- 
distance), among states (interurban), or among countries and continents (international) (Brunekreeft \& Gross, 2000). Communications that cross networks are normally authorized and regulated by state or provincial departments within a country, or by internationally regulated departments found at the other end of the communication. In connecting longdistance calls, the infrastructure between two users in different states or countries has been made by cable, point-to-point radio communication, or via satellite.

In some countries, infrastructure was improved when, for instance, cable was replaced by fiber optics (Cox et al., 1993). The difference in the actual communication was not perceived by the client or by any regulatory department because the change happened in the communication protocols found inside the metallic cables, fiber optics, radio, or satellite links. The new technology was capable of compressing the data twice as much as the old technology while still guaranteeing the same quality of service (Reynolds \& Rix, 2001). For the user, the conventional telephone remained the same because nothing changed in relation to the protocol for the client; instead, the changes were among the long-distance connections. In other words, the change happened when communication left the central exchange (PBX) of a provider from a specific state, went to another state, and entered the internal network of a company (intranet). Figure 1 shows the point at which the system was modified, providing the interconnection without the user or government perceiving any change because the changes are made only in the hosts' transmission and reception (gateways) equipment that converts the analog or digital signals into voice signals for Internet protocol (IP) (Chen et al., 2007). The communications using satellite links via microwave or underground fiber optics have not been changed, only some of the new equipment in the boundaries among service provider links (as shown in Figure 1). The circled parts in the figure show the changes made to insert the new equipment, permitting the use of VoIP protocol. This also allows the sharing of the same channel of communication by voice, data, and image with little deterioration in quality of service (QoS), to guarantee the priority of transmission (Chen et al., 2007). QoS is a technical term used to guarantee band and define the priorities of communication, since the Internet priority level is not as high as voice communication. 


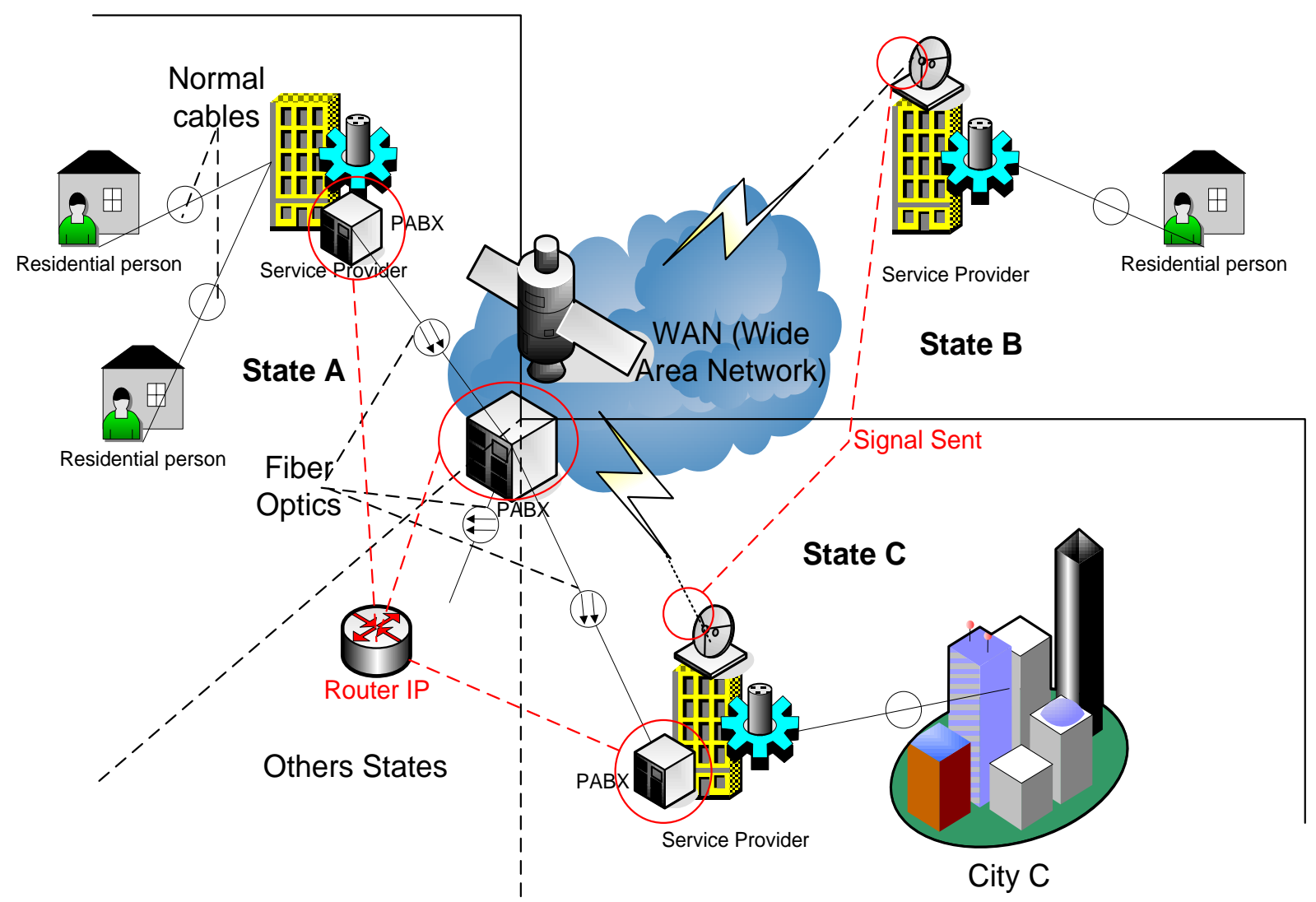

Figure 1. Interstate or international connection using the conventional system and the points of convergence to use the new technology.

\subsection{LONG-DISTANCE MOBILE COMMUNICATION}

In the beginning the mobile communications industry was very local, with mobile providers having towers with cellular antennas that supported communication within the projected cell area. As communication expanded to include a fixed or mobile number in another town, state, or country, mobile providers partnered with landline companies using their physical infrastructure to transport long-distance communication (Fig.2). The dotted line represents the points of modification to guarantee the autonomy of the mobile provider and the transmission of communication with the new technology. Figure 2 is a little more complex, concerning the use of sharing among providers and the disconnection of the landline provider. 


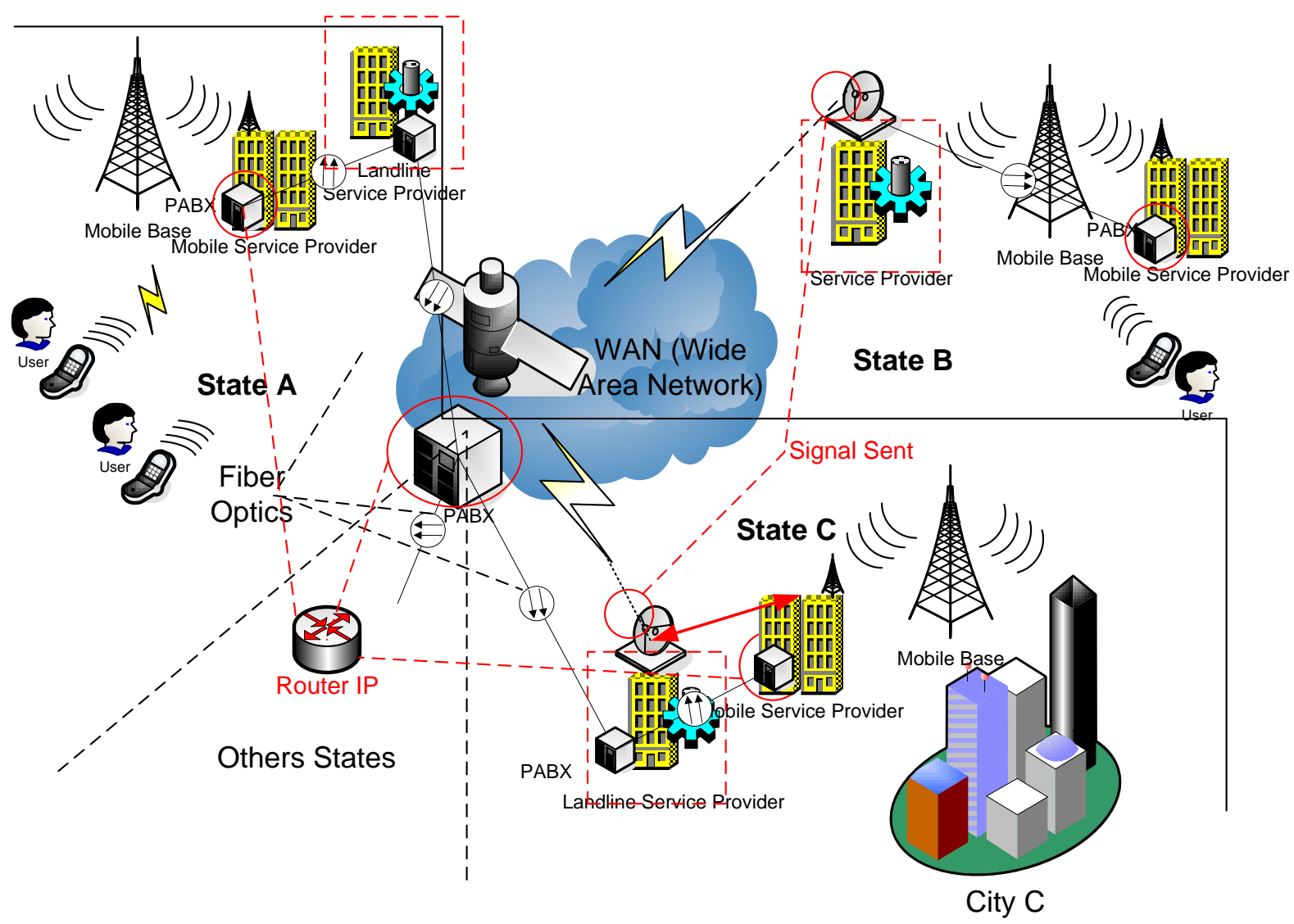

Figure 2. Interstate or international connection using the conventional system, and sharing connectivity between the mobile and landline providers.

The mobile network has continued to improve as mobile service providers have expanded their underground interconnectivity infrastructure (Chou \& Liu, 2006). By implementing these changes, mobile providers have gained total autonomy in most communications and interconnectivities, with the exception of a few access points that continue to use shared partnership through rental of a satellite band or fiber optic connection for sporadic use by the mobile provider. As sharing among connections were almost eliminated and it was possible to complete a call autonomously (Blumberg et al., 2006), mobile companies also inserted data technology that reduced the band necessary for longdistance voice communication. In this respect, the mobile companies invested directly in VoIP technology right from the beginning, guaranteeing long-distance communication among their consumers using their own infrastructure and reducing the need to share landline networks. 


\subsection{LONG-DISTANCE INTEGRATION COMPANIES}

In large countries such as the USA, the cost of infrastructure development is high and pioneering companies have been able to optimize their present structure among providers (Crandall, 1997). The biggest companies have benefited the most (Davies et al., 2004) since they have been able to share the surplus in their bandwidth or in their schedule of use with other companies. Some landline and mobile phone companies that have expanded their infrastructure to provide long-distance services to large scale consumers have increased their business by selling or renting bandwidth (Green, 1999).

Smaller companies, or companies with limited reach, have adopted the unique solution of renting from the largest companies. With dedicated rented links, and using connections via fiber optics or satellite, the main emphasis was on the implemented protocol as well as the boundary host equipment. Even though the communication had to be converted and reconverted on reception, the quantity of hosts or communication points crossed did not affect the speed and quality of service provided (Habib \& Chuang, 2007). These companies operated VoIP connections for international calls between two landline companies and developed what they called an international voice call center (Van de Klundert et al., 2005). For instance, using an international card the user calls a free number, hears a digital operator explaining how to continue the call, dials the other country's number, and the call transfers as a local call. Between the countries, the transmission and reception are realized between the landline companies and the users across a data link as VoIP technology. While these sources increase the number of service providers in a particular market, they create regulatory challenges as discussed below.

\section{NON-REGULATED CONVERGENCE}

Based on the SI presented above, and in the services provided by the landline and mobile providers, service convergence allows transmission of a voice call as if it were data to long-distance locations. This reduces costs due to the technology applied as well as taxes saved. Since there is no regulation for VoIP systems, voice communication is only evaluated when the conventional voice system is used via a landline or mobile network. The models developed for price-cap regulation and rate-of-return (ROR) regulation do not take into account integration among different technologies (Lewis \& Sappington, 1989).

Service convergence in the mobile communication industry has made the regulatory oversight scenario even worse. Previously, the regulator had control of the actual interurban mobile phone calls when the system was shared between landline and mobile providers. This is because when a cell phone call is taken out of its local area it informs the closest tower of its location and code of use, and the tower in that area is obliged to send the data to a landline to connect the two different areas (state or country). With the autonomous systems developed by mobile operators, it is no longer easy to determine the location of a mobile phone because only the mobile provider has this information. Without any regulation equipment capable of controlling all calls, it is difficult to identify the number being called or the location of the originating call, except by the mobile provider. 
Different technologies have different regulations, and in some cases, such as in the USA, these regulations change between state and federal levels (Cherry, 2007). Another factor in the USA is vertical integration, as many telecommunication providers offer landline, mobile, Internet, and television at the same time. These integrations are internal to a specific provider, which connects a call via many diverse routes by taking advantage of TC (Shin, 2005; Santos et al., 2008).

Figure 3 shows three connections based on different services that can provide good voice communication with different costs and the same approximate quality. Table 1 shows the difference in costs based on the kind of service. In this example, a ten minute voice communication between Brazil and the USA is priced in three different ways. The first case uses VoIP between two Internet points and does not take into account the ADSL connection fee as it is used for many different purposes, so the monthly fee is included in general use and the connection cost is free for this kind of voice communication. The second case uses a normal landline and does not take into account the line rental fee for both phones based on the fact that the phone has other uses. In this way, the consumer will pay more than US\$10 (ten minutes' usage). Landline costs are charged based on minutes used. In the last case, not including the Internet fee (origin) and the telephone fee (destination), the cost is just the local charge, which is a few cents per minute.

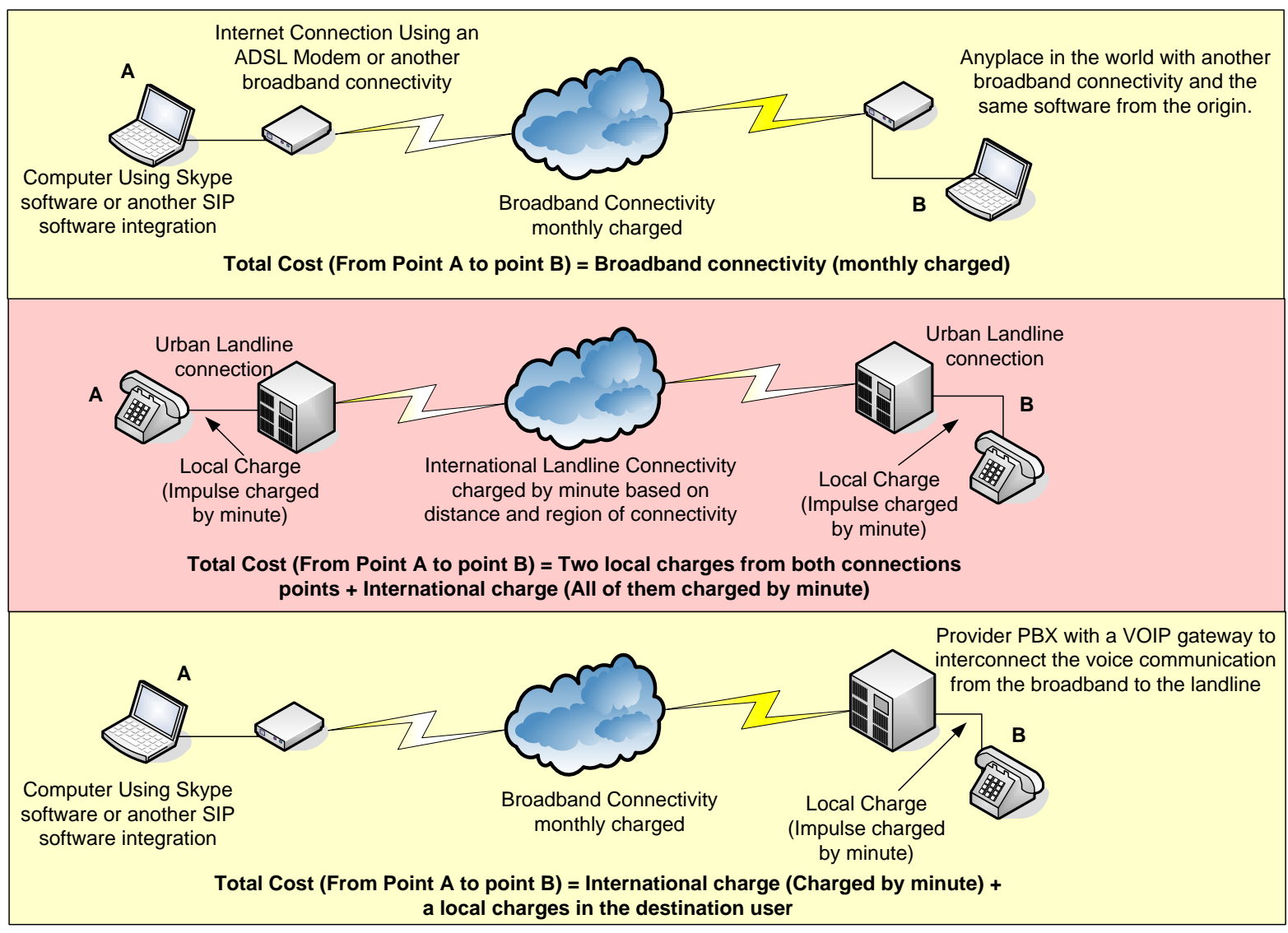

Figure 3. Voice communication using different services and connectivity. 
When a company uses VoIP between its branches for internal communications it is an entrepreneurial connectivity (fair use). Nevertheless, when a company uses the technology to integrate countries and continents without paying any fee to the government for the international connectivity, and when they are commercializing the service, they have an advantage over other companies using normal technology. Even when providers use the same technology, reduce the resources needed to connect two clients, and save on infrastructure requirements, the final price to consumers remains the same; this is unfair to end consumers that are still paying old prices for new technologies, despite savings in connectivity benefitting providers.

Table 1. Service costs for various long-distance connectivity methods, charged or not.

\begin{tabular}{llll}
\hline Technology / & Broadband & International \\
Communication & connection fee & $\begin{array}{l}\text { communication } \\
\text { comarge }\end{array}$ & Extra fees \\
\end{tabular}

VoIP between two Internet points US\$40 per $1 \mathrm{MB}$ ADSL

International voice communication via landline No US $\$ 40$ per $1 \mathrm{MB}$ ADSL

Internet point and a landline point

\author{
E.g. US\$1 per \\ minute from
} Brazil to USA
No

No

A few cents Phone fees per minute in (Landline both sides monthly charged)

A few cents Phone fees per minute in (At the both sides reception point)

It was predicted that the competitive purpose of using new technologies was that providers would offer the best prices, increasing competition in the market; however, in countries with lobbying, poor regulation, and poor social responsibility, providers prefer to maintain high prices and unfairly increase their profits instead of profiting by increasing use and users. 


\section{COMPETITIVENESS REGULATION PROJETC}

The problem created by SI, TC, and non-regulation is one of an uneven competitive field where smaller companies are at a disadvantage, especially when they are authorized to offer only one single service. Larger companies are able to employ different technologies, taking advantage of convergence (Gill, 2008) to reduce costs. Figure 4 shows the distribution between price and connectivity in this market. The matrix clearly shows two things.

1) that competition is currently being defined by technology; and

2) that it is very difficult to maintain competitiveness, or generate regulation in the voice communication services by treating each technology separately (Zhou, 2003; Peha \& Tewari, 1998; Van de Klundert et al., 2005).

\section{Price}

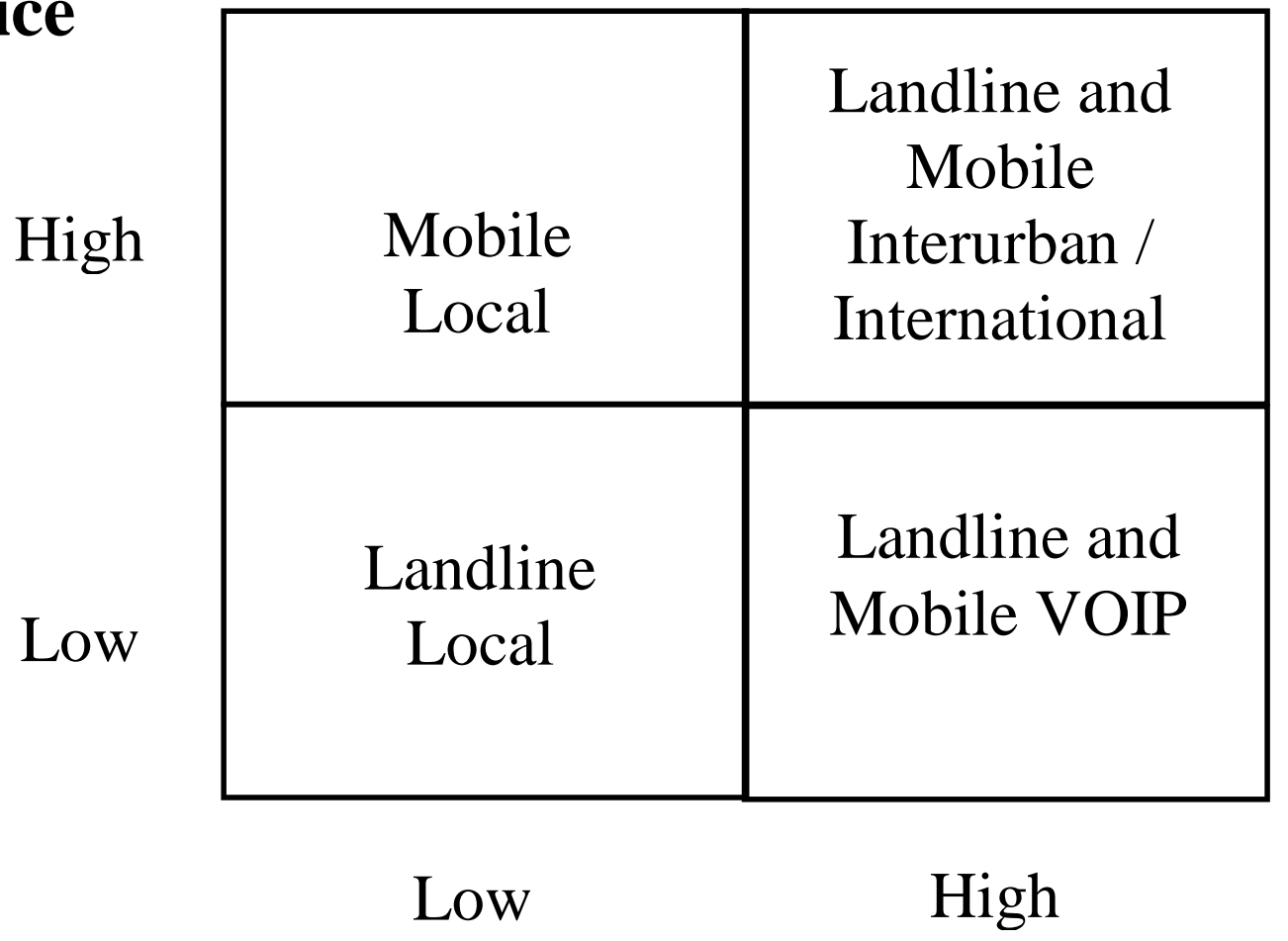

Distance

Figure 4. Technology, communication, and price matrix.

For instance, we can have intense price competition between mobile operators. However, if we adopt a universal number portability system, it increases the opportunity for customers to switch not only between mobile providers but also between technologies. In this case, small and large service providers would operate on a more level playing field and offer 
services that reflect the real costs of delivering quality communications. These technologies are complementary, interacting, converging, and sometimes being added to guarantee communication with better quality and security. For regulation to serve the public interest, including maintenance of competition, identical services (local and long distance) should focus on the service offered and not on the underlying technologies. The authors believe that instead of regulating a specific technology, the regulatory focus should be on ensuring services that are similar, irrespective of technology. Today, it is possible to develop voice communication through the Internet, which can be provided by a telephone company as well as an Internet company. This shifts the focus and the challenges in determining costs and prices for specific services. Although technologies have different costs based on their infrastructures and investments, the challenges should not deter the regulatory authorities from determining the costs of operation and development in order to define how to tax similar services developed by different technologies.

As discussed previously, the current regulations favor larger companies, which are able to take advantage of technological convergence to reduce costs without paying higher fees to the government or lowering prices for the customers. Large companies benefit from current regulatory focus because of their greater reach (Mansell, 1997) but it creates an unfair horizontal competitive field. It becomes difficult for smaller VoIP companies to form and compete.

To address this disadvantage, a couple of different projects have been started around the world to generate new forms of competition. For example, in Italy the Mobile Virtual Network Operator (MVNO) (Kim \& Seol, 2007) has been set up to sell mobile communication but without any direct investment in the infrastructure of the sector. The MVNO operates as a new mobile company with specific numbers, brands, pre-paid cards, account sites, and credit access; it uses the infrastructures of existing companies, searching and finding offers in the market, partnering with the company that offers the best terms, and renting the mobile phone numbers and a portion of the communication system. The technology connectivity is maintained by the telecommunication provider, which benefits from the increased number of users even if it means sharing their commercial work.

Figure 5 shows the technologies' convergence in different services simultaneously. It illustrates the limitations and possibilities when, for example, television is run via an Internet connection (Santos et al, 2008; Shin, 2005), occupying another interesting market (Buskirk et al., 2007). With the advent of WiMAX (Martikainen, 2006), it will be possible to connect through the Internet from anywhere, accessing Internet bandwidth inside a car, in the middle of the street, using a notebook, PDA, or other wireless equipment (Sanmateu et al., 2002). A small PDA with integrated VoIP software will be able to use voice communication without costs or fees in the telecommunication sector based on Internet access provided by the WiMAX. This would create unfair competition in the mobile communication sector, so all these factors would have to be considered in determining future market competitiveness. 


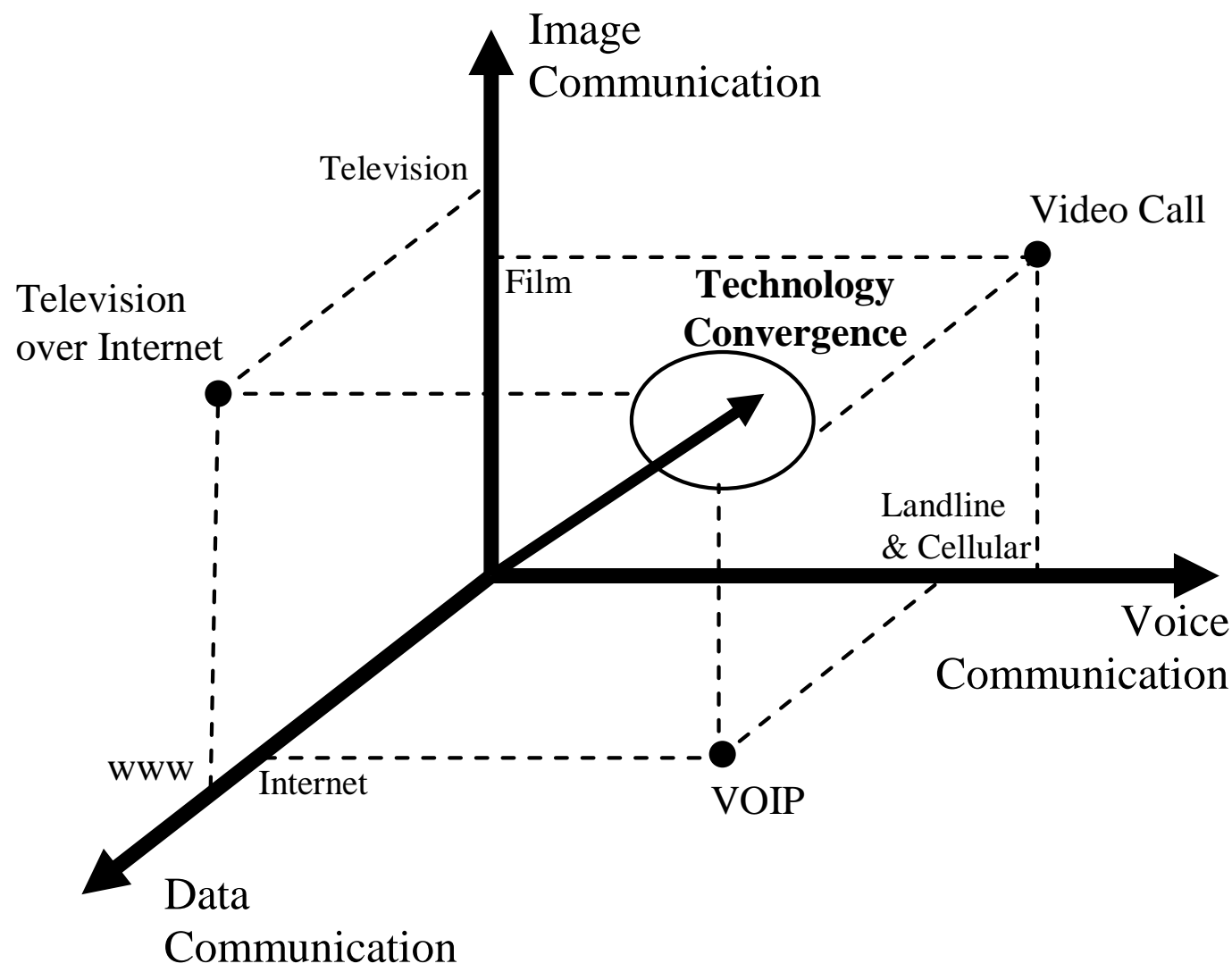

Figure 5. Technology convergence in the telecommunications sector.

These factors need to be evaluated carefully in order to promote commonweal as well as fair competition. VoIP, for example, could be regulated as voice communication, which, if used between two computers via an Internet network, would be free of costs since it is an added-value service. However, when VoIP is complementing or integrating other services, with the technology applied in the intranet network of a provider or integrated to a gateway converter to connect with a PABX, it has to be considered as integral to voice communication and therefore eligible for all taxes and fees. To regulate and control the protocols which are being used by the telecommunication companies, we offer the following alternatives.

\subsection{PROPOSITION 1}

A managerial network service could be inserted in the service providers' networks, guaranteeing that all communications would be evaluated in parallel and all protocols related to VoIP would be evaluated automatically as well. It could verify destinations and origins to compel providers to develop proxies to block unauthorized VoIP traffic. If the final IP number is a router without a MAC address, this would automatically be a convergence proxy charged by its use. Communication via the Internet through the use of computers or dedicated without 
QoS should be registered by the free software offered, even when the VoIP is without cost. The only way to maintain and guarantee the order is by registering all software, making a commitment to provide the necessary regulating data for each call when it is not targeted at another PC. All systems using VoIP protocol that are not registered or authorized must be blocked in the international network (Cherry, 2005). This way, the security of communication and the rules will be guaranteed.

Two factors should be verified. The first is when the QoS factor does not exist in the Internet. Then it would interpret it as a professional service without a minimum of communication quality needed in the sector. The second consideration is when VoIP is part of an integrative service to companies that have a private data link; data links rented or sold to subcontractors should be controlled by the protocol used. However, it will not be possible to commercialize the system without prior authorization from the responsible regulatory authority in the telecommunications sector, and not in the Internet sector.

Inside the intranet with a guaranteed bandwidth, QoS could be applied guaranteeing the quality of communication. This level of quality does not exist yet in the Internet, so when a dedicated link develops the communication, it can charge by the service developed. The cost will still be less for the user and will generate profit for the company, as well as guaranteeing fair competition to telecommunications companies that either use or do not use VoIP technology.

\subsection{PROPOSITION 2}

Another alternative would be to regulate and charge all long-distance services as VoIP and integrated conventional communication. A provider without the necessary integration to use VoIP should rent this capability from a competitor with a mandate to update their infrastructure. Since VoIP is a technology that has been in the market for some time, it is likely that it would be the technology used by all providers. This proposition favors use of technologies to create efficiencies in the system and to pass the savings on to the consumers.

As we look ahead, and as new technologies enter the market and a new VoIP protocol capable of bandwidth reduction for transmission becomes available, there could be a twostage plan of introduction and use. First, the new technology should be available for internal use in the companies or in the Internet to accomplish adaptation and market tests. Once a new technology is proven capable of guaranteeing at least the same level of quality, service, and other technological requirements and the pioneering company is able to recover its investment, then further savings should be passed on to consumers and the use of the technology by other service providers should be encouraged. The objective should be to encourage competing companies to use the same efficient technology as quickly as possible (Yung-Ching \& Tsui-Hsu, 2006). Doing this will motivate all service providers to use updated or state-of-the-art technology. In such a case, companies that choose to keep obsolete or out-of-date technology should not be protected by regulators and their cost calculations. 


\section{CONCLUSION}

The goal of this paper was to highlight the need for regulation to guarantee a fairer competitive playing field among different telecommunication providers and to encourage innovation through new products and technologies. The main problem today stems from technological complexity which makes it difficult for regulators and even large customers to identify and protect user interests. While integrated technologies allow products and services to be bundled, current regulations continue to evaluate the services separately, creating rules for each service as an independent system. The cost reduction benefits of SI and TC are not transferred to the users.

This problem is more severe in other parts of the world. For example, in Brazil, compared to the USA and Europe, there is a much lower emphasis on reducing costs and increasing competition in the market. Given the global nature of the telecommunications industry, the development of regulations that are more appropriate to the state of technology developments and their impact on market competition can make a big difference.

\section{REFERENCES}

Blumberg, S. J., Luke, J. V., \& Cynamon, M. L. (2006). Telephone coverage and health survey estimates: Evaluating the need for concern about wireless substitution. American Journal of Public Health, May, 96(5), 926.

Brunekreeft, G. \& Gross, W. (2000). Prices for long-distance voice telephony in Germany. Telecommunications Policy, 24, 929-945.

Buskirk, B., Schmidt, S. M. P., \& Ralph, D. L. (2007). Patterns in high-tech firms' growth strategies by seeking mass mainstream customer adaptations. The Business Review, 8(1), 34.

Carpenter, P. \& Lapuerta, C. (1999). A critique of light-handed regulation: The case of British Gas, February 1999. Northwestern Journal of International Law \& Business, 19(3), 479.

Cicekli, E. (2011). Antecedents of normative integration in multinational companies: A conceptual model. International Journal of Management. 28(4), 177-183.

Chen, J.-L., Chen, M.-C., \& Chian, Yi-Ru (2007). QoS management in heterogeneous home networks. Computer Networks, 51, 3368-3379.

Cherry, S. (2005). The VoIP backlash. IEEE Spectrum, 42(10), 61-63.

Cherry, B. A. (2007). The telecommunications economy and regulation as co-evolving complex adaptive systems: Implications for federalism. Federal Communications Law Journal, 59(2), 369. 
Chou, Y. \& Liu, K.-C. (2006). Paradoxical impact of asymmetric regulation in Taiwan's telecommunications industry: Restriction and rent seeking. Telecommunications Policy, 30, 171-182.

Cohen, T., Mattila, O., \& Southwood, R. (2005). VoIP and regulation. Global Symposium for Regulators (GSR), Hammamet, Tunisia, November 14-15, 2005. http://www.itu.int/osg/spu/newslog/VoIP+And+Regulation.aspx, International Telecommunications Union (ITU).

Cox, L. A. Jr., Kuehner, W. E., Parrish, S. H., \& Qiu, Y. (1993). Optimal expansion of fiberoptic telecommunications networks in metropolitan areas. Interfaces, 23(2), 35-48.

Crandall, R. W. (1997). Are telecommunications facilities 'infrastructure?' If they are, so what? Regional Science and Urban Economics, 27, 161-179.

Davies, G., Hardt, M., \& Kelly, F. (2004). Come the revolution: Network dimensioning, service costing and pricing in a packet switched environment. Telecommunications Policy, $28,391-412$.

De Boer, D. B. \& Evans, L. (1996). The economic efficiency of telecommunications in a deregulated market: The case of New Zealand. Economic Record, 72, 216-239.

Fennel, J. W. Jr. \& Gobioff, B. D. (1983). A satellite communications controller. IBM Systems Journal, 22(1-2), 80.

Fenton, C., Nigeon, B., Willis B., \& Harris, J. (2000). Wireless access. BT Technology Journal, Jul 2000, 18(3), 74.

Gill, T. (2008). Convergent products: What functionalities add more value to the base? Journal of Marketing, 72(2), 46-62.

Green, W. (1999). Unlocking the potential of outsourcing. Telecommunications, 33(8), 77.

Habib, A. \& Chuang, J. (2007). Improving application QoS with residential multihoming. Computer Networks, 51, 3323-3337.

Hameria, A. P. \& Paatela, A. (2005). Supply network dynamics as a source of new business. Int. J. Production Economics, 98, 41-55.

Han, J. K., Chung, S. W., \& Sohn, Y. S. (2009). Technology convergence: When do consumers prefer converged products to dedicated products? Journal of Marketing, 73(4), 97-108.

Hobday, M., Davies, A., \& Prencipe, A. (2005). Systems integration: A core capability of the modern corporation. Industrial and Corporate Change, 14(6), 1109-1143. 
Jussawalla, M. (1999). The impact of ICT convergence on development in the Asian region. Telecommunications Policy, 23, 217-234.

Kim, B. W. \& Seol, S. H. (2007). Economic analysis of the introduction of the MVNO system and its major implications for optimal policy decisions in Korea. Telecommunications Policy, 31, 290-304.

Korzeniowski, P. (2001). VoIP - Still only a drop in the bucket. Business Communications Review, 31(2), 78.

Lee, G. K. (2007). The significance of network resources in the race to enter emerging product markets: The convergence of telephony communications and computer networking, 1989-2001. Strategic Management Journal, 28(1), 17.

Lewis, T. R. \& Sappington, D. E. M. (1989). Regulatory option and price-cap regulation. The Rand Journal of Economics, 20(3), 405.

Liu, F., Chou, W., Guo, W., \& Wong, W. E. (2005). An approach to integrating SIP in converged multimodal / multimedia communication services. Telecommunication Systems, 28(3), 387-405.

Maeda, T., Amar, A.D., Gibson, A. (2006). Impact of wireless telecommunications standards and regulation on the evolution of wireless technologies and services over Internet protocol. Telecommunications Policy 30, 587-604.

Mansell, R. (1997). Strategies for maintaining market power in the face of rapidly changing technologies. Journal of Economic Issues, 31(4), 969.

Martikainen, O. E. (2006). Complementarities creating substitutes - Possible paths towards 3G, WLAN/WiMAX and ad hoc networks. The Journal of Policy, Regulation and Strategy for Telecommunications, Information and Media, 8(4), 21-32.

Nunes, P., Wilson, D., \& Kambil, A. (2000). The all-in-one market. Harvard Business Review, 78(3), 19-21.

Pathak, J. (2005). Risk management, internal controls and organizational vulnerabilities. Managerial Auditing Journal, 20(6), 569.

Peha, J., \& Tewari, S. (1998). The results of competition between integrated-services telecommunications carriers. Information Economics and Policy, 10, 127-155.

Reynolds, R. J. B. \& Rix, A. W. (2001). Quality VoIP: An engineering challenge. BT Technology Journal, 19(2), 23.

Sanmateu, A., Paint, F., Morand, L., Tessier, S., Fouquart, P., Sollund, A., \& Bustos, E. (2002). Seamless mobility across IP networks using mobile IP. Computer Networks, 40, 181-190. 
Santos, J., Gomes, D., Sargento, S., Aguiar, R. L., Baker, N., Zafar, M., \& Ikram, A. (2008). Multicast / broadcast network convergence in the next generation mobile networks. Computer Networks, 52, 228-247.

Sappington, D. E. M. (2005). Regulating service quality: A survey. Journal of Regulatory Economics, 27(2), 123-154.

Shelanski, H. A. (2007). Adjusting regulation to competition: Toward a new model for US telecommunications policy. Yale Journal on Regulation, 24(1), 55.

Shin, D. H. (2005). Technology convergence and regulatory challenge: A case from Korean digital media broadcasting. The Journal of Policy, Regulation and Strategy for Telecommunications, 7(3), 47.

Trebing, H. M. (2004). Assessing deregulation: The clash between promise and reality. Journal of Economic Issues, 38(1), 1.

Van de Klundert, J., Kuipers, J., Spieksma, F. C. R., \& Winkels, M. (2005). Selecting telecommunication carriers to obtain volume discounts. Interfaces, 35(2), 124.

Xavier, P. \& Ypsilanti, D. (2007). Universal service in an IP-enabled NGN environment. The Journal of Policy, Regulation and Strategy for Telecommunications, Information and Media, 9(1), 15-31.

Yung-Ching, H. \& Tsui-Hsu, T. (2006). The impact of dynamic capabilities with market orientation and resource-based approaches on NPD project performance. Journal of American Academy of Business, 8(1), 215.

Zhou, H. (2003). Integration and access regulations in telecommunications. Information Economics and Policy, 15, 317-326. 